\title{
Evaluation of mandibular range of motion in Brazilian children and its correlation to age, height, weight, and gender
}

\section{Letícia Mêlo de Sousa ${ }^{(a)}$ Harumi Martins Nagamine(a) Thaís Cristina Chaves ${ }^{(b)}$ Débora Bevilaqua Grossi(c) Simone Cecílio Hallak Regalo(d) Anamaria Siriani de Oliveira ${ }^{(e)}$}

(a) PTs, Graduate Students of Physical Therapy, School of Medicine of Ribeirão Preto, University of São Paulo.

(b) PT, PhD, MS in Medical Sciences; (c) PhD, Professor; (e)PT, PhD, Professor

- Department of Biomechanics, Medicine and Rehabilitation of the Locomotor System, School of Medicine of Ribeirão Preto, University of São Paulo.

(d) PhD, Professor, Department of Morphology, Stomatology and Physiology, School of Dentistry of Ribeirão Preto, University of São Paulo.

\begin{abstract}
This study aimed to measure the active mandibular range of motion (ROM) (mouth opening: MO; right and left lateral movements: RL and LL; protrusion: P) in Brazilian children of both genders and of various ages, weights, and heights, and to establish correlations among such variables. Study subjects $(\mathrm{n}=303)$ were healthy boys and girls, with ages ranging between 6 and 14 years, who were regular students of a public school in the state of São Paulo. Analysis of variance and intra-class correlation coefficients were considered significant for $\mathrm{p}<0.05$. Weak significant correlations were observed between mandibular ROM and age, height, and weight. No statistically significant differences $(\mathrm{p}>0.05)$ were observed regarding mandibular ROM between gender groups. Mean mandibular ROM values showed significant increases $(p<0.05)$ in relation to age, height, and weight, except for RL ( $p>0.05$ ), in the studied age range. Significantly smaller $(\mathrm{p}<0.05)$ mean mandibular ROM values were observed for the intervals of 6 and 7 years of age, 1.15$1.35 \mathrm{~m}$, and $17.30-26.50 \mathrm{~kg}$, in relation to the other ranges. Nonetheless, no differences were observed among mean mandibular ROM values in the ranges 8 to $12-14$ years, $1.36-1.75 \mathrm{~m}$, and $47-85 \mathrm{~kg}$. Thus, it is suggested that weight, height, and age variables be considered when obtaining mandibular ROM values, particularly in children aged 6 to 7 years, measuring 1.15-1.35 m, and weighing between $17.3-46.5 \mathrm{~kg}$.
\end{abstract}

Descriptors: Temporomandibular joint; Range of motion, articular; Movement.

\author{
Corresponding author: \\ Anamaria Siriani de Oliveira \\ Faculdade de Medicina de \\ Ribeirão Preto - USP \\ Campus Universitário, Curso de \\ Fisioterapia - Prédio Central \\ Av. Bandeirantes, 3900 - Monte Alegre \\ Ribeirão Preto - SP - Brazil \\ CEP: 14049-900 \\ E-mail: siriani@fmrp.usp.br
}




\section{Introduction}

Temporomandibular joint (TMJ) range of motion (ROM) assessment is a simple and objective method used to perform a functional evaluation of the masticatory system. ${ }^{1,2}$ Reduced or excessive mandibular mobility may be one of the signs of temporomandibular disorder (TMD), which may also be associated with traumas, neuromuscular disorders, odontogenic infections, and development abnormality. ${ }^{3-10}$ Thus, mandibular ROM measurement becomes a useful parameter in diagnosis and treatment planning, and is therefore recommended in clinical exams of patients with TMD signs and symptoms. ${ }^{4,11}$

Mandibular ROM values are influenced by numerous factors, including joint and muscle structure conditions, ethnicity, age, weight, gender, and height. . $^{1,4,712-15}$ Hence, it is essential to establish a population's mandibular ROM in order to obtain appropriate and reliable diagnosis regarding movement limitation. ${ }^{4}$ Agerberg ${ }^{16}$ (1974) proposed cuttoff values of $40 \mathrm{~mm}$ for mouth opening, and $5 \mathrm{~mm}$ for protrusive and lateral horizontal movements. The author also suggested using different limits of mouth opening for men, women, and children $(42 \mathrm{~mm}, 38 \mathrm{~mm}$, and $35 \mathrm{~mm}$, respectively). ${ }^{16,17}$ Landtwing $^{12}$ (1978) and Vanderas ${ }^{10}$ (1992) have also stated that it is important to take into consideration the age and height of subjects when evaluating mandibular ROM. Boozer et al. ${ }^{1}$ (1984) studied, with the use of a millimeter ruler, the influence of age and gender on the mouth opening range of 2,273 North-Americans aged between 11 and 70 years. The authors observed that mouth opening values reduced with age and tended to be higher for men. Similar results have been presented in other studies. ${ }^{4,11,18}$ Sheppard, Sheppard ${ }^{15}$ (1965), in a similar but broader study involving North-American subjects, aged between 11 and 15 years, stated that the highest mouth opening values were found within the age range of 11 and 15 years, with a progressive increase in measurement for children aged between 3 and 15 years. Other authors have evaluated maximum mandible movement in specific populations: Agerberg ${ }^{17}$ (1974), in Scandinavian children aged 1 to 2 and 5 to 6 years;
Rothenberg 9 (1991), in North-American individuals aged 4 to 14 years; and Vanderas ${ }^{10}$ (1992), in Greek children aged 6 to 10 years. They found that the mouth opening range increased with age. However, no significant correlation was confirmed between range and the child's gender, the opposite of that stated for adults. ${ }^{7,16,19}$

The data presented above demonstrates the importance of mandibular movement measurement in the evaluation of the functional status of the masticatory system and associated structures. Factors which may influence mandibular ROM values must be taken into consideration, such as age, gender, and height of the individual. Nevertheless, no studies that evaluate such correlations in Brazilian children were found. Thus, the objective of this research was to study mandibular ROM values in Brazilian children (boys and girls) of various ages, weights, and heights, and establish correlations among these variables and mandibular ROM values.

\section{Material and Methods}

The subjects of this study are 303 children $(1.37$ r $0.11 \mathrm{~m} ; 33.7$ r $10.9 \mathrm{~kg})$ from a public school in the city of Ribeirão Preto, São Paulo State, Brazil. The children were 6 to 14 years old, of which 161 were girls (9.0 r 1.6 years) and 142 were boys (8.8 $\mathrm{r} 1.6$ years).

Inclusion criteria were: no history of trauma on the face, having all incisors, being able to understand and perform mandibular movements as instructed, and having good health. Children were excluded from the study if they were in orthodontic treatment, if they had any pain or restriction in mandible movement, and any systemic disease, such as juvenile rheumatoid arthritis. This study was approved by the Research Ethics Committee, School of Medicine of Ribeirão Preto, University of São Paulo.

Weights and heights were obtained using an anthropometric scale (Filizola ${ }^{\square}$, São Paulo, SP, Brazil), with precision of $100 \mathrm{~g}$. Measurements of maximum active mandibular ROM were made by the same trained rater, using a calibrated boley gauge (Mitutoyo $^{\square}$, Suzano, SP, Brazil). Mouth opening (MO), right $(\mathrm{RL})$ and left $(\mathrm{LL})$ lateral movements, and pro- 
trusion $(\mathrm{P})$ were recorded in millimeters $(\mathrm{mm})$, in 3 consecutive repetitions, at random, and following the Research Diagnostic Criteria for Temporomandibular Disorders (RDC/TMD). ${ }^{19}$

Mean mandibular ROM values were analyzed according to age, height, and weight ranges, which were arbitrarily determined for statistical ends. Hence, the sample was divided into 7 age groups with a one year variation $(6,7,8,9,10,11$, and 12-14 years), 5 height groups with a variation of approximately $10 \mathrm{~cm} \quad(1.15$ to $1.25 \mathrm{~m} ; 1.26$ to $1.35 \mathrm{~m} ; 1.36$ to $1.45 \mathrm{~m} ; 1.46$ to $1.55 \mathrm{~m} ; 1.56$ to $1.75 \mathrm{~m}$ ), and 5 weight groups with a variation of approximately $10 \mathrm{~kg}$ (17.30 to $26.50 \mathrm{~kg} ; 27$ to $36.50 \mathrm{~kg} ; 37$ to $46.50 \mathrm{~kg} ; 47$ to $56.50 \mathrm{~kg}$ and 57 to $85 \mathrm{~kg}$ ). Children who were 12,13 , and 14 years old were put in the same group due to the small number of participants in this age range $(n=9$, $\mathrm{n}=2$, and $\mathrm{n}=1$, respectively). Analysis of variance (ANOVA) $(\mathrm{p}<0.05)$ was used to evaluate the differences among the 3 repeated measures of mandibular ROM values in the different age, weight, gender, and height groups. Differences in gender groups were compared using Student's $t$-test for independent samples $(\mathrm{p}<0.05)$.

Mandibular ROM values were correlated with weight, height, and age data using Pearson's Correlation test $(\mathrm{p}<0.05)$, or Pearson's $\mathrm{r}$. Correlation levels were classified as poor for $\mathrm{r}<0.3$, weak for $0.3<\mathrm{r}<0.5$, moderate for $0.6<\mathrm{r}<0.8$, and excellent for $\mathrm{r}<0.8 .{ }^{20}$

\section{Results}

Weak statistically significant correlations $(0.3<\mathrm{r}<0.5)$ were found between the variables

Table 1 - Pearson's $r$ values obtained from the correlations between mean ROM and the variables age, weight, and height. ( $n=303$ ).

\begin{tabular}{c|c|c|c|c}
\hline Variable & $\mathrm{MO}$ & $\mathrm{RL}$ & $\mathrm{LL}$ & $\mathrm{P}$ \\
\hline Age (years) & $0.32^{*}$ & $0.32^{*}$ & $0.33^{*}$ & $0.32^{*}$ \\
\hline Height $(\mathrm{m})$ & $0.41^{*}$ & $0.41^{*}$ & $0.41^{*}$ & $0.41^{*}$ \\
\hline Weight $(\mathrm{kg})$ & $0.36^{*}$ & $0.35^{*}$ & $0.35^{*}$ & $0.36^{*}$ \\
\hline
\end{tabular}

MO: mouth opening; RL and LL: right and left lateral movements; $\mathrm{P}$ : protrusion. *Pearson's $r$ and $p<0.05$. age, height, and weight, and all the evaluated ROM (Table 1).

Girls showed mean MO values of $43.47 \mathrm{r} 5.99 \mathrm{~mm}$ and boys, of $43.96 \mathrm{r} 5.60 \mathrm{~mm}$ (Student's $t$ test, $\mathrm{p}=0.47$ ). For RL and LL movements, respectively, the mean values observed were $8.31 \mathrm{r} 2.07 \mathrm{~mm}$ and $8.14 \mathrm{r} 2.08 \mathrm{~mm}$ for girls, and $8.42 \mathrm{r} 1.89 \mathrm{~mm}$ and $8.27 \mathrm{r} 1.84 \mathrm{~mm}$ for boys (Student's $t$ test, $\mathrm{p}=0.62$ and 0.59 , respectively). The values observed for $\mathrm{P}$ movement were $7.01 \mathrm{r} 2.55 \mathrm{~mm}$ for girls, and $7.16 \mathrm{r} 2.39 \mathrm{~mm}$ for boys (Student's $t$ test, $\mathrm{p}=0.58$ ).

No differences were found in terms of gender and mandibular ROM values in the evaluated children. They were, therefore, placed in the same group. As for age range and mean $\mathrm{MO}$ values, no significant differences were found between ages 6 and 7. Nonetheless, there was a significant difference $(\mathrm{p}<0.05)$ in relation to the other ages, with a significant increase $(\mathrm{p}<0.05)$ at 8 years and maintenance of the mean $\mathrm{MO}$ values in subsequent ages. No differences were observed among the ages considered in the present study and mean RL values. The same was observed for mean LL values, which varied slightly, except between ages 7 and 10, which presented statistically significant values $(p<0.05)$. As for mean $P$ values, a significant increase $(\mathrm{p}<0.05)$ was observed for the mean values in 10 and 12-14 year-old children when compared to ROM values of 7 yearolds (Table 2).

In regard to the height range and mean $\mathrm{MO}$ values, the latter showed a significant increase $(\mathrm{p}<0.05)$ with height, except for the ranges 1.36$1.45 \mathrm{~m}$ and $1.56-1.75 \mathrm{~m}$. Similar results were found for mean values of RL and P. As for mean LL values, there was a significant increase in relation to the increase in height ranges, with non-significant increases $(\mathrm{p}>0.05)$ only for heights within the range 1.46 to $1.55 \mathrm{~m}$ (Table 3 ).

Analysis of mean mandibular ROM values in relation to weight showed a significant increase in MO values $(\mathrm{p}<0.05)$ for weights within the range 17.30 to $46.50 \mathrm{~kg}$, which remained unchanged in the following weight ranges. The same behavior was observed for mean RL, LL, and P values ( $\mathrm{Ta}-$ ble 4). 
Evaluation of mandibular range of motion in Brazilian children and its correlation to age, height, weight, and gender

Table 2 - Mean values and standard deviations of mandibular ROM $(\mathrm{mm})$ according to the studied age ranges and the complete sample $(n=303)$.

\begin{tabular}{|c|c|c|c|c|}
\hline Age (years) & MO & $\mathrm{RL}$ & LL & $P$ \\
\hline $6(n=18)$ & 39.44 r 4.42 & 8.05 r 2.02 & 7.77 r 1.65 & 7.11 r 2.65 \\
\hline $7(n=51)$ & 40.10 r $5.81^{*}$ & 7.90 r 1.82 & 7.41 r 2.13* & 6.12 r 2.22* \\
\hline $8(n=57)$ & 43.56 r $5.19^{*}$ & 8.57 r 1.92 & 8.23 r 1.71 & 7.00 r 2.69 \\
\hline $9(n=54)$ & 45.16 r 5.41 & $8.68 \times 1.93$ & 8.33 r 2.14 & 7.16 r 2.34 \\
\hline $10(n=64)$ & 44.97 r 5.71 & 8.55 r 2.16 & 8.64 r $1.91^{*}$ & 7.75 r 2.30* \\
\hline $11(n=47)$ & 45.86 r 5.96 & 8.10 r 2.03 & $8.36 r 1.93$ & 7.24 r 2.18 \\
\hline $12-14(n=12)$ & 44.22 r 4.44 & 8.39 r 1.88 & 8.33 r 1.84 & 8.48 r 2.00* \\
\hline Total $(n=303)$ & 43.70 r 5.81 & 8.20 r 1.97 & 8.36 r 1.99 & 7.10 r 2.44 \\
\hline
\end{tabular}

MO: mouth opening; RL and LL: right and left lateral movements; P: protrusion; ${ }^{*} p<0.05$ in ANOVA.

Table 3 - Mean values and standard deviations of mandibular ROM (mm) according to the studied height ranges.

\begin{tabular}{|c|c|c|c|c|}
\hline Height (m) & MO & RL & $\mathrm{LL}$ & $P$ \\
\hline $1.15-1.25(n=49)$ & 39.59 r $5.21^{*}$ & 6.88 r 1.90* & 6.72 r $2.07^{*}$ & $5.26 r 2.29^{*}$ \\
\hline $1.26-1.35(n=80)$ & 42.27 r 5.03* & 7.91 r 1.70* & 7.74 r $1.72 *$ & 6.49 r $2.12^{*}$ \\
\hline $1.36-1.45(n=103)$ & 44.52 r 5.43 & 8.68 r 1.89 & 8.53 r 1.80* & 7.46 r 2.31 \\
\hline $1.46-1.55(n=55)$ & 46.44 r 5.49* & 9.27 r $1.77^{*}$ & $9.11 \times 1.67$ & 8.23 r 2.28* \\
\hline $1.56-1.75(n=16)$ & 48.74 r 4.93 & 9.94 r 1.49 & 9.74 r $1.49^{*}$ & 9.15 r 2.12 \\
\hline
\end{tabular}

$\mathrm{MO}$ : mouth opening; RL and LL: right and left lateral movements; P: protrusion; ${ }^{*} \mathrm{p}<0.05$ in ANOVA.

Table 4 - Mean values and standard deviations of mandibular ROM ( $\mathrm{mm}$ ) according to the studied weight ranges.

\begin{tabular}{|c|c|c|c|c|}
\hline Weight (kg) & MO & $\mathrm{RL}$ & $\mathrm{LL}$ & $P$ \\
\hline $17.30-26.50(n=90)$ & 40.69 r 5.00* & 7.32 r 1.80* & 7.16 r $1.88^{*}$ & 5.77 r $2.15^{*}$ \\
\hline $27-36.50(n=120)$ & 43.71 r 5.47* & 8.40 r $1.90^{*}$ & 8.25 r $1.85^{*}$ & 7.13 r 2.32* \\
\hline $37-46.50(n=52)$ & 46.79 r 5.47* & 9.41 r 1.77* & 9.23 r $1.71^{*}$ & 8.38 r 2.36* \\
\hline $47-56.50(n=26)$ & 46.20 r 5.21 & 9.16 r 1.69 & 8.97 r 1.63 & 8.09 r 2.28 \\
\hline $57-85(n=15)$ & 46.57 r 6.31 & 9.22 r 2.05 & 9.07 r 1.97 & 8.24 r 2.54 \\
\hline
\end{tabular}

MO: mouth opening; RL and LL: right and left lateral movements; P: protrusion; ${ }^{p} p<0.05$ in ANOVA.

\section{Discussion}

The objective of this research was to study mandibular ROM values in Brazilian children, boys and girls, of various ages, weights, and heights, and establish correlations between these variables and mandibular ROM values.

No statistically significant differences were observed regarding the mandibular ROM of the gender groups. The present study's findings agree with those of Rothenberg ${ }^{9}$ (1991), Vanderas ${ }^{10}$ (1992), and Agerberg $^{17}$ (1974), who also did not find any differences between ROM values in relation to children's gender. Hence, it is suggested that the influence that gender has on ROM in adults is not observed in children, perhaps due to the fact that they do not have the sexual maturity of adults.

Mean maximum mandibular ROM values, taking into consideration all the children evaluated in this 
study, were 43.70 r $5.81 \mathrm{~mm}$ for $\mathrm{MO}, 8.20$ r $1.97 \mathrm{~mm}$ for RL, 8.36 r $1.99 \mathrm{~mm}$ for LL, and $7.10 \mathrm{r} 2.44 \mathrm{~mm}$ for P. Similar values have been reported in previous studies of non-Brazilian children. , $^{10,17,21,22}$

In the present study, weak and positive statistically significant correlations were observed between the variables age, height, and weight, and all the evaluated ROM. A significant increase in mean MO values was found for ages 6 and 7 in relation to the other ranges, which remained unchanged in subsequent age ranges. A significant increase was also observed in mean MO values for the weight range from 17.30 to $46.50 \mathrm{~kg}$, which remained constant in subsequent weight ranges. As for height, an increase was observed for each range. Thus, the present study's results suggest that small height ranges, of approximately $10 \mathrm{~cm}$, can be considered as a better predictor of MO normality values. As for age and weight, however, results suggest that due to the small variation in mean MO values, some of the ranges considered in the present study may be grouped together. Therefore, although children aged less than 6 years were not evaluated, the present study suggests that single groups may be considered with ages up to 7 years, from 8 to 14 years, and weighting $47.0 \mathrm{~kg}$ or more. Future studies should be performed to confirm this suggestion.

Rothenberg9 (1991) also observed, in subjects with ages between 4 and 14 years old, a positive correlation between $\mathrm{MO}$ values and age, as well as in relation to weight and height, with a mean $\mathrm{MO}$ value of 43.99 r $5.78 \mathrm{~mm}$. Similar results were obtained by Landtwing ${ }^{12}(1978)$ and Henrikson et al. ${ }^{23}$ (2000). Rothenberg ${ }^{9}$ (1991) and Fukui et al. ${ }^{3}$ (2002) also suggest there is a correlation between facial morphology, which varies according to age, gender, and ethnicity, ${ }^{24-28}$ and mandibular movements. Such relation had previously been confirmed by Ingervall ${ }^{2}$ (1971), who suggests that approximately 25 to $40 \%$ of interindividual variations in mandibular ROM may be due to variations in facial morphology.

Regarding the influences of the studied variables on the values of RL and LL, it was observed that age had a smaller influence than height and weight. As for $\mathrm{P}$, all the studied variables appeared to cause changes in mean values. For height ranges below
$1.45 \mathrm{~m}$, there were gradual increases in mean values of RL, LL, and P, which did not remain constant in higher height ranges. Weight also seems to have an important role, particularly in weight ranges below $46.5 \mathrm{~kg}$, which showed a gradual increase in RL, LL, and $\mathrm{P}$ values. Studies that evaluate mandibular lateral and protrusive movements in children are scarce in the literature. Of the existing studies, only a few describe the obtained results. Among such studies are those by Rothenberg ${ }^{9}$ (1991) and Vanderas ${ }^{10}$ (1992). Both report an increase in those movements with age, but they do not present any mean values in their studies. As for height, Vanderas ${ }^{10}$ (1992) only states there was a positive correlation between that variable and mandibular movements, but does not describe the behavior.

Thus, considering the correlation observed in the present study and the significant increase in the mandibular ROM mean values among the age, height and weight ranges, it is suggested that, for the determination of normality values specifically for clinical practice, such variables should be considered. To that end, the present study contributes with preliminary data.

\section{Conclusion}

The present research studied mandibular ROM in Brazilian children (boys and girls) with ages between 6 and 14 years. The findings suggest there is a weak correlation between the variables age, weight, and height and the degree of mandibular ROM, with significant differences between the obtained mean values. Thus, it is suggested that weight, height, and age variables be considered when obtaining mandibular ROM values, particularly in children aged 6 to 7 years, measuring 1.15-1.35 m, and weighing between 17.3-46.5 kg. Moreover, there is a need for further studies to evaluate the influence of facial morphology on mandibular ROM in Brazilian children.

\section{Acknowledgements}

We thank the Quantitative Methods Center (CEMEQ), School of Medicine of Ribeirão Preto, for the statistical study of data. We also wish to thank the State of São Paulo Research Foundation (FAPESP, process number 2004/14372-8). 


\section{References}

1. Boozer CH, Ferraro EF, Weinberg R. The effects of age, race and sex on the interincisal measurement. Ann Dent. 1984;43(2):5-7.

2. Ingervall B. Variation of the range of movement of the mandible in relation to facial morphology in young adults. Scand J Dent Res. 1971;79(2):133-40.

3. Fukui T, Tsuruta M, Murata K, Wakimoto Y, Tokiwa H, Kuwahara Y. Correlation between facial morphology, mouth opening ability, and condylar movement during opening-closing jaw movements in female adults with normal occlusion. Eur J Orthod. 2002;24(4):327-36.

4. Gallagher C, Gallagher V, Whelton H, Cronin M. The normal range of mouth opening in an Irish population. J Oral Rehabil. 2004;31(2):110-6.

5. Helkimo M. Studies on function and dysfunction of the masticatory system. II. Index for anamnestic and clinical dysfunction and occlusal state. Sven Tandlak Tidskr. 1974;67(2):10121.

6. Ingervall B. Range of movement of mandible in children. Scand J Dent Res. 1970;78(4):311-22.

7. Lewis RP, Buschang PH, Throckmorton GS. Sex differences in mandibular movements during opening and closing. Am J Orthod Dentofacial Orthop. 2001;120(3):294-303.

8. Pehling J, Schiffman E, Look J, Shaefer J, Lenton P, Fricton J. Interexaminer reliability and clinical validity of the temporomandibular index: a new outcome measure for temporomandibular disorders. J Orofac Pain. 2002;16(4):296-304.

9. Rothenberg LH. An analysis of maximum mandibular movements, craniofacial relationships and temporomandibular joint awareness in children. Angle Orthod. 1991;61(2):103-12.

10. Vanderas AP. Mandibular movements and their relationship to age and body height in children with or without clinical signs of craniomandibular dysfunction: Part IV. A comparative study. ASDC J Dent Child. 1992;59(5):338-41.

11. Szentpétery A. Clinical utility of mandibular movement ranges. J Orofac Pain. 1993;7(2):163-8.

12. Landtwing K. Evaluation of the normal range of vertical mandibular opening in children and adolescents with special reference to age and stature. J Maxillofac Surg. 1978;6(3):157-62.

13. Muto T, Kanazawa M. The relationship between maximal jaw opening and size of skeleton: a cephalometric study. J Oral Rehabil. 1996;23(1):22-4.

14. Pullinger AG, Liu SP, Tay D. Differences between sexes in maximum jaw opening when corrected to body size. J Oral Rehabil. 1987;14(3):291-9.
15. Sheppard IM, Sheppard SM. Maximal incisal opening - A diagnostic index? J Dent Med. 1965;20(1):13-5.

16. Agerberg G. Maximal mandibular movements in young men and women. Sven Tandlak Tidskr. 1974;67(2):81-100.

17. Agerberg G. Maximal mandibular movements in children. Acta Odontol Scand. 1974;32(3):147-59.

18. Mezitis M, Rallis G, Zachariades N. The normal range of mouth opening. J Oral Maxillofac Surg. 1989;47(10):10289.

19. Dworkin SF, LeResche L. Research diagnostic criteria for temporomandibular disorders: review, criteria, examinations and specifications, critique. J Craniomandib Disord. 1992;6(4):300-55.

20. Chan YH. Biostatistics 104: Correlational Analysis. Singapore Med J. 2003;44(12):614-9.

21. Bonjardim LR, Gavião MBD, Pereira LJ, Castelo PM. Mandibular movements in children with and without signs and symptoms of temporomandibular disorders. J Appl Oral Sci. 2004;12(1):39-44.

22. Leles RC, Moreira Neto JJS, Giro EMA, Compagnoni MA. Valores normais da amplitude do movimento mandibular em crianças. Pós-Grad Rev Fac Odontol São José dos Campos. 2000;3(2):121-6.

23. Henrikson T, Nilner M, Kurol J. Signs of temporomandibular disorders in girls receiving orthodontic treatment. A prospective and longitudinal comparison with untreated Class II malocclusions and normal occlusion subjects. Eur J Orthod. 2000;22(3):271-81.

24. Ajayi EO. Cephalometric norms of Nigerian children. Am J Orthod Dentofacial Orthop. 2005;128(5):653-6.

25. Buschang PH, Gandini Júnior LG. Mandibular skeletal growth and modelling between 10 and 15 years of age. Eur J Orthod. 2002;24(1):69-79.

26. Farkas LG, Katic MJ, Forrest CR, Alt KW, Bagic I, Baltadjiev $\mathrm{G}$ et al. International anthropometric study of facial morphology in various ethnic groups/races. J Craniofac Surg. 2005;16(4):615-46.

27. Ishii N, Deguchi T, Hunt NP. Morphological differences in the craniofacial structure between Japanese and Caucasian girls with Class II division 1 malocclusions. Eur J Orthod. 2002;24(1):61-7.

28. Scavone H, Trevisan H, Garib DG, Ferreira FV. Facial profile evaluation in Japanese-Brazilian adults with normal occlusions and well-balanced faces. Am J Orthod Dentofacial Orthop. 2006;129(6):721-5. 